\title{
The Current Role of Whole-Body Autoradiography in the United States
}

\author{
William J. Waddell and Carolyn Marlowe \\ Department of Pharmacology and Toxicology \\ University of Louisville School of Medicine \\ Louisville, KY 40292 USA
}

As we approach the 40th anniversary of the original publication on whole-body autoradiography by Ullberg in 1954 ${ }^{1}$, it seems appropriate to review the progress and future of this technique. This paper is intended to be an overview from our personal perspective and an analysis of the current use and role of whole-body autoradiography (WBA) in the United States. The purpose is to give our perception of how WBA should be used in drug distribution studies. Acceptance of the utilization of WBA in drug distribution studies has been slower in the United States than in Europe or Japan. One of the incentives for undertaking this review was to attempt to find an explanation for this reluctance. Although no clear explanation emerged, the impression is that concern over quantitation of WBA is probably one of the limiting factors. Another impression is that many scientists, including those in regulatory agencies, do not fully appreciate the unique advantage in quantitating areas of inhomogeneity in tissues made possible by WBA.

In order to put the current activity for WBA in the USA in perspective with the rest of the world, we searched MEDLINE for all papers on WBA since January 1990. As one can see in Table 1, published papers on the procedure in Europe exceeded those in the U.S. and Japan combined. This does not necessarily reflect the activity of WBA; indeed, estimates of the number of companies using the technique in these three geographical areas would suggest that a higher percentage of studies are published in the U.S. than in either Europe or Japan ${ }^{2)}$. Further breakdown of the laboratories of origin in the U.S. of papers published during this approximate three-year interval, indicates that although an approximately equal number of industrial and academic labs publish, the number of papers from the academic labs exceeds those from industry (Table 2). In fact, the results of our survey, described below, revealed that the academic institutions publish an average of $45 \%$ of their WBA studies whereas the non-academic labs published an average of only $17 \%$ of their studies.

We prepared a survey in an effort to get better insight into how WBA is being used in the United States. This survey was sent to users of WBA known to us in the United States. Of the forty-seven surveys mailed out, twenty-three different labs returned questionnaires; five of these were from academic institutions, the remainder were from industry and contract laboratories. It was not possible to distinguish in some cases whether the lab did WBA for in-house purposes or under contract.

The average number of years of experience reported for performing WBA was 9.3 with a range of less than one year to 28 years. The average number of people in each group was 2.5 with a range of $1-8$ people. Eighty-three percent of these labs reported an increasing use of WBA, four labs reported 
Table 1 Countries of Origin of Papers in MEDLINE on Whole-Body Autoradiography (January 1990-October 1993)

\begin{tabular}{lrlrlr}
\hline Sweden & 14 & USA & 21 & Japan & 20 \\
Germany & 7 & Canada & 3 & China & 3 \\
U.K. & 6 & & & & \\
Finland & 3 & & & & \\
France & 3 & & & & \\
Norway & 3 & & & & \\
Hungary & 2 & & & & \\
Portugal & 2 & & & & \\
Italy & 1 & & & & \\
Switzerland & 1 & & & & \\
\hline Europe & 42 & North America 24 & Asia & 23
\end{tabular}

Table 2 Laboratories of Origin in the U.S.A. of Papers in MEDLINE on Whole-Body Autoradiography (January 1990-October 1993)

\begin{tabular}{ll}
\hline $\begin{array}{l}\text { Industry } \\
\text { (7 Papers) }\end{array}$ & Academia (14 Papers) \\
Ciba-Geigy & University of Louisville \\
Genentech & University of Massachusetts \\
Monsanto & $\begin{array}{l}\text { University of Medicine \& Dentis- } \\
\text { try, NJ }\end{array}$ \\
NeoRx Corp. & University of North Carolina \\
Wallace Labs. & University of Texas, Galveston \\
& Utah State University
\end{tabular}

decreasing use and four indicated the use has not changed in recent years.

This survey indicates that the labs studied an average of 6.3 compounds per year with a range of $0-$ 30 compounds. Only $21.7 \%$ of the compounds studied are published in archival literature; the range was $0-100 \%$. The range of isotopes currently being used by the respondents was surprisingly wide; Table 3 lists the isotopes being used by these laboratories. It is no surprise that ${ }^{14} \mathrm{C}$ is the most frequently used with ${ }^{3} \mathrm{H},{ }^{125} \mathrm{I}$ and ${ }^{35} \mathrm{~S}$ following in that order. We did find it interesting that seven respondent laboratories do not use ${ }^{14} \mathrm{C}$. This is partially explained by a few of the laboratories being those in nuclear medicine where there is limited interest in the distribution of organic compounds. Also, some labs confine their studies to ${ }^{125} \mathrm{I}$.

The wide variety of isotopes reminds us that one must consider the sensitivity ${ }^{3)}$ and resolution of the various types of X-ray film. Once whole-body, freeze-dried sagittal sections have been taken, many opportunities exist for localization not only with a wide variety of isotopes but also with other analytical methods. Histochemical, fluorescent and other procedures lend themselves well to the unique specificity of localization that can be found in these sections. In the survey, 30\% of the labs stated that histochemistry is done in parallel with WBA. The question was not asked, but perhaps should be in the future, of which labs only use the sections for histochemistry or other non-isotope methods of analysis for the chemical of interest. This could be an increasingly important use of whole-body, freeze-dried sagittal sections. We have found histochemistry to be a very informative aspect of our investigations ${ }^{4-6}$.

Another important question that frequently arises in discussion of WBA is the chemical nature of the radioactivity seen in the autoradiograph. Thirty-five percent of the respondents in the survey stated that extraction, together with HPLC or other techniques, were used in conjunction with WBA. Ullberg ${ }^{1)}$ early on recognized the opportunity for this verification. We and others have identified the chemical nature of the radioactivity in specific areas of the sections by cutting out areas of interest, extracting with appropriate solvents, and subjecting the extract to chromatography or other suitable techniques to verify the chemical nature of the radioactivity ${ }^{7-9)}$. If the tissue section used for autoradiography provides an 
Table 3 Survey on Current Use of WBA Isotopes Currently Being Used by Respondents:

\begin{tabular}{rcc}
\hline Isotopes & No. of Labs & $(\%)$ \\
\hline${ }^{14} \mathrm{C}$ & 18 & $(86 \%)$ \\
${ }^{3} \mathrm{H}$ & 13 & $(62 \%)$ \\
${ }^{125} \mathrm{I}$ & 11 & $(52 \%)$ \\
${ }^{35} \mathrm{~S}$ & 4 & $(19 \%)$ \\
${ }^{99 \mathrm{~m}} \mathrm{Tc}$ & 3 & $(14 \%)$ \\
${ }^{111} \mathrm{In}$ & 3 & $(14 \%)$ \\
\hline
\end{tabular}

${ }^{131} \mathrm{I},{ }^{32} \mathrm{P},{ }^{54} \mathrm{Mn},{ }^{153} \mathrm{Gd},{ }^{201} \mathrm{Tl}$ were used by two responding laboratories.

${ }^{123} \mathrm{I},{ }^{157} \mathrm{Dy},{ }^{65} \mathrm{Zn},{ }^{59} \mathrm{Fe},{ }^{45} \mathrm{Ca},{ }^{67} \mathrm{Ga},{ }^{95} \mathrm{Nb},{ }^{97} \mathrm{Ru}$ and ${ }^{113 \mathrm{~m}} \mathrm{Sn}$ were used by one responding laboratory.
Table 4 Survey on Current Use of WBA Quantitation by Photometric Densitometry or Phosphorluminesence: $65 \%$ of respondents

\begin{tabular}{lc}
\hline \multicolumn{1}{c}{ Brand } & Number \\
\hline LOATS & 4 \\
Molecular Dynamics & 4 \\
AMBIS & 3 \\
Fuji & 1 \\
Amersham & 1 \\
Other & 6 \\
\hline
\end{tabular}

inadequate quantity of isotope for chemical analysis, one can take adjacent, thicker sections to use for removal of the areas for extraction. Subjecting the sections to ultraviolet light and observing fluorescence is another method of identifying fluorescent compounds in discrete areas of the section ${ }^{10)}$. One is only limited by imagination and ingenuity in devising other ways of using the sections for identifying the chemical nature of substances in discrete areas of the sections.

Current discussion among scientists knowledgeable about WBA is the appropriateness of including results from WBA studies in the data submitted to regulatory agencies. In our survey on current use of WBA in the United States, $78 \%$ of the laboratories indicated the results of their studies would be submitted to regulatory agencies. Only nine percent indicated their results would not be submitted to regulatory agencies; there was no response from $13 \%$. Sixty-three percent of the respondents would favor the FDA and other agencies requiring results of WBA studies instead of dissection studies. The remainder of the respondents would favor not requiring WBA or favor requiring both techniques. Interestingly, $74 \%$ of the respondents are currently doing the dissection and counting method in parallel with WBA.

Perhaps one of the most frequently discussed aspects of WBA is the quantitation of radioactivity in specific areas of the sections. Sixty-five percent of the respondents are quantitating the radioactivity either by photometric densitometry or radioluminescence. Table 4 shows the breakdown of brands of instruments being used by those investigators. The unpublished survey of Warrender ${ }^{2)}$ of industrial laboratories in the U.S., Europe and Japan asked a similar question on quantitation of radioactivity levels in WBA sections. The results of that survey were in close agreement with ours; $69 \%$ of the 14 companies responding from the U.S. quantitate levels of radioactivity in the sections. Further, Warrender's survey showed that virtually the same percentage (68\%) of companies in Europe quantitate, whereas in Japan only $24 \%$ of companies do quantitation.

The subject of quantification deserves special attention because it is so frequently misunderstood, particularly by those not aware of the potential of WBA. Figure 1 illustrates the concept with which one must continually be aware in performing any analytical procedure involving a biological sample from an animal. The simplest and, of course, rudimentary level of analysis is that of the entire body. Analysis of 


\begin{tabular}{|c|c|c|}
\hline Whole Body & Organ & Intraorgan Areas \\
\hline & $\begin{array}{l}\text { e.g. } \\
\text { Liver, } \\
\text { Brain, } \\
\text { etc. }\end{array}$ & $\begin{array}{l}\text { e.g. } \\
\text { Periportal, } \\
\text { Hippocampus, } \\
\text { etc. }\end{array}$ \\
\hline $\begin{array}{l}\text { Cell Layers } \\
\text { e.g. } \\
\text { Duct Epithelium, } \\
\text { Theca Interna, } \\
\text { etc. }\end{array}$ & $\begin{array}{l}\text { Specific Cell } \\
\text { e.g. } \\
\text { Alveolar Type II, } \\
\text { Macrophage, } \\
\text { etc. }\end{array}$ & \\
\hline $\begin{array}{l}\text { Subcellular Organelle } \\
\text { e.g. } \\
\text { Nucleus, } \\
\text { Mitochondria, } \\
\text { etc. }\end{array}$ & $\begin{array}{l}\text { Molecule } \\
\text { e.g. } \\
\text { DNA, } \\
\text { Ah Receptor, } \\
\text { etc. }\end{array}$ & \\
\hline
\end{tabular}

Figure 1 Schematic representation of different biological levels for quantitative analysis of drug interactions

a whole animal homogenate could indeed give both the average level of drug in the entire body as well as the percentage of original dose to great precision. However, one has no idea whether all of this remaining drug was homogeneously distributed throughout the mouse or concentrated solely in some specific but unknown cell type. It was obvious that some degree of localization could be obtained by dissection and removal of specific organs. This technique of dissection and organ analysis was instituted many years ago and continues today. One only has to consider the complexity of organs and the ultimate goal of the analytical process to realize how truly imperfect organ analysis is. No organ consists of a single homogeneous molecule with the possible exception of red cells. Even in the liver, with anatomically apparently identical hepatocytes, there is now recognition that hepatocytes in the periportal area and those around the central vein have different distributions of enzymes and other constituents. Furthermore, organs contain cell layers that have specific functions. The epithelium lining the ducts and passages in the pancreas, mammary gland, salivary gland, lung, etc., have specialized functions which set them apart from the rest of the organ; these cell layers assume additional importance since it is from these cell layers that carcinomas arise ${ }^{11,12)}$. Analysis of a whole organ gives virtually no more information on the concentration in these cell layers than would an analysis of the average concentration in a whole animal.

Some organs contain a wide variety of cells. For example the lung contains about 40 different cell types each with a specialized function ${ }^{13)}$. For example, the alveolar type II cell synthesizes surfactants and has been shown by autoradiography to be the sole cell type accumulating the herbicide paraquat ${ }^{14)}$. Even with a single cell type the interior of the cell is not homogeneous. Subcellular organelles have discrete, diverse functions. The ultimate goal of course is to discern which molecule or molecules within a cell the experimental drug or chemical has interacted. Somehow some scientists and regulatory agencies appear to have lost sight of this architectural arrangement of living organisms. There are limitations and unique problems with any technique attempting to identify and quantitate a drug or chemical in one of these specific sites in the architecture of a living body. Our consideration of quantitating a drug in specific areas can start with the crude attempt to localize by dissection. One is limited by purely physical constraints in how small an area within an organ a dissection can be accomplished. Although the 
mucosa of the intestine can be scraped and an estimate made of the concentration in this multicell layer, isolation of epithelial layers from other organs can be increasingly difficult. Consider the manual dexterity required to isolate the ductal epithelium of the salivary gland of the mouse or the theca interna of corpora lutea in a mouse ovary ${ }^{11,15)}$. Certainly dissection is impossible at this level and even more discrete areas. For practical purposes dissection is limited to relatively large areas within organs. Even then the tissue removed may be altered by an unknown quantity of blood or other fluids.

Some comment also needs to be made about analytical techniques that start at the other end of our continuum. Indeed some molecules within cells can be isolated and interactions between that molecule and the drug of interest can be studied in vitro. However, that interaction ignores the dynamic state of living tissue and the interdependence of cell structures upon each other for function. One can use the paraquat example again to illustrate distribution of chemicals in vivo from those in vitro ${ }^{14)}$. Merely allowing lung tissue, which was frozen immediately, to thaw destroys the distribution that was present in vivo. This is apparently because the compound does not interact with any specific intracellular molecule but is there merely because of an active transport process.

The information obtained from the two methods, dissection and WBA, need to be compared (Tables 5-6). One also needs to keep in mind the difference between precision and accuracy. Judgment is necessary in deciding which and how much of each of these factors is important in analyzing a biological sample. We suggest that dissection is limited, for practical purposes, to resolution only of some intraorgan areas. Also, since the number of intraorgan areas of interest can increase to overwhelming numbers there are truly practical limitations to the dissection and counting technique. The only advantage of the dissection method is that with a sufficient amount of tissue the precision of the analysis can be very good. A radioactive sample in a scintillation vial can be counted until the number of dpms is known with great precision. However, when this sample is a homogenate or an average value from more than one cell type the accuracy of the concentration in any of these cells is zero. All of that drug could be in one cell type and none in another cell type.

By comparison, WBA offers enormous and unique advantages over dissection. The concentration in specific cell layers and even specific cell types can be readily determined. Many people confuse the preci-

Table 5 Dissect, Digest and Count Method

- Major advantage: great precision is possible for sample analyzed.

- Chemical identification of radioactivity is possible but not always done.

- Major disadvantage: assumes homogeneity throughout tissue sample. Very low accuracy if distribution is not homogeneous; even contribution from blood may be in error.

Table 6 Whole-body Autoradiographic Method

- Major advantage is detection of inhomogeneity of distribution within tissue.

- For nonhomogeneous tissue, accuracy greatly exceeds that of dissection method.

- Much more likely to provide mechanistic data than dissection method.

- Chemical identification of radioactivity may be more difficult than dissection method.

- Perceived disadvantage is degree of precision in quantitation. 
sion available from dissection with the accuracy possible from WBA. Admittedly, the precision of analysis of WBA may not reach the level that may be attained by dissection. However, the importance of knowing the location within the body's architecture of the chemical in question far outweighs any limitation in the precision of the analysis by WBA. One cannot overemphasize the importance of these distinctions.

An additional advantage with WBA is that the level of resolution is more likely to provide mechanistic data than the poor resolution available from dissection. The localization of drug in specific cell layers or individual cells frequently suggests a mechanism of action from what is known about that specific cell's function in the organ ${ }^{15)}$. For example, the Clara cell in the lung is known to contain P450 enzymes which oxidize substrates. Localization of radioactivity in this cell layer consequently provides suggestive evidence for the metabolism by these enzymes as one of the explanations for its localization in that cell. Further studies can then be done with specific inhibitors of those enzymes to provide additional evidence for or against that mechanism ${ }^{15,16)}$. With analysis of the entire lung, localization only in Clara cells does not provide a concentration sufficiently high in the organ to detect and study, even if the localization is confined to Clara cells. Many other examples of mechanistic data from resolution at the cellular layer obviously could be cited. The closer one gets to a reaction with a specific chemical in the cell the closer one gets to the definitive explanation of the drug's action.

Occasionally it is said that analysis by using whole organs provides a larger amount of sample and consequently chemical identification can be done. We have noted that frequently even with dissection and counting, chemical identification of the radioactivity is still not always done. In addition, small tissues (e.g. adrenal or ovary) may not provide much more tissue than could be obtained from a thick frozen section. The inhomogeneity of adrenal and ovary makes it impossible to know whether the radioactivity counted in these whole organs is uniformly distributed, confined to the medulla, one of the layers of the cortex, the corpora lutea, theca interna, etc. The lack of information from dissection and counting the entire organ is in sharp contrast to the knowledge obtained from WBA of the specific area of the organ which contains the radioactivity. Alternate methods of determining the chemical nature of the radioactivity in whole-body sections have been cited earlier in this paper.

There seems to be a widespread, perceived notion that precision from WBA is not adequate. Consequently, the possible sources of error in quantitation of WBA needs inspection. Table 7 lists some of the most likely sources of error. Autoradiographs stored for long periods of time, at least several months, may experience some fading of the latent image. This can be minimized by lowering the temperature during exposure. A much more common source of error which apparently is not controlled as routinely

Table 7 Possible Sources of Error in Quantitation of Whole-Body Autoradiographs

- Fading of latent image

- Positive or negative chemography

- Variation in section thickness (intra- and inter-)

- Differences in self absorption of radioactivity among tissues

- Consistency of X-ray film development procedure

- Linearity of X-ray film 
as could be desired is positive or negative chemography. Some sensitive X-ray films can be readily affected by the chemicals naturally present in biological tissues. Sometimes these chemicals will produce or at least enhance an image on X-ray film. Some constituents of biological tissues can decrease the image on $\mathrm{X}$-ray film that would otherwise be produced by radioactivity in that tissue. Laboratories should do the appropriate controls, i.e., store sections with no radioactivity against unexposed and fully exposed X-ray film to determine whether those sections might be producing positive or negative chemography in that film.

Another potential source of error is variation in section thickness, both intrasection and intersection. Fortunately any significant variations are usually apparent by visual observation of the sections. Small variations obviously can go unnoticed by visual observations but with most microtomes in use today and with experienced operators such variations should not be a significant problem. Another closely related potential problem is differences in self-absorption of radioactivity among tissues. This is rarely a problem with ${ }^{14} \mathrm{C}$ and sections no thicker than $20 \mu$. Even in sections thicker than $20 \mu$, the only tissues likely to produce any self-absorption are bone and teeth. For other tissues it has been shown that in sections up to $100 \mu$-thick there is no significant self-absorption ${ }^{17)}$.

The developmental procedure for X-ray film can cause differences in density of the film if the solutions are not properly controlled regarding the quantity of film developed, shelf-life, temperature, etc. Another characteristic of X-ray film is that its density is linear with radioactivity only over a fairly narrow range. One must recognize this limitation when attempting to quantitate radioactivity from density of X-ray film.

There are several reports on the details of quantitation of $\mathrm{WBA}^{3,17-22)}$. These reports deal only with the use of X-ray film and photometric densitometry. We have not included the new technique of phosphorimaging because we understand it is currently under extensive evaluation in Japan, and the results of this evaluation will be presented as part of this Forum. We look forward to the results of that evaluation. The commercial instruments currently available for photometric densitometry all appear to give very good quantitation of the density of X-ray film. This does not seem to be a limitation to quantitation in the use of X-ray film over the range of linearity.

The results of the reports on quantitation can be summarized as follows (Table 8). There are commercial ${ }^{14} \mathrm{C}$ standards, as well as procedures for preparing laboratory standards, which provide adequate calibration for WBA. The simplest, and perhaps the best, procedure for quantitation is to compare the density of the film over each tissue to the density of that over blood. These concentrations relative to blood in many instances are all that are needed. Further refinement of these relative values can be ac-

Table 8 Summary of Reports on Quantitation of WBA

- ${ }^{14} \mathrm{C}$ standards provide adequate calibration

- Radiographic density is linear for sections $10 \mu$ to $100 \mu$

- Radioactivity vs film density is linear if kept within range of film

- Temperature and length of exposure affect slope but not linearity

- Commercial film is very reproducible

- WBA and dissection provide comparable precision 
complished by parallel experiments in which the actual concentration in blood is determined at each of the time points used for the autoradiographic studies.

The radiographic density in film is linear for section thicknesses of 10-100 $\mu^{17)}$. In addition, radioactivity vs. film density is linear if kept within the linear range of the film. Obviously, fully exposed film cannot measure increased levels of radioactivity. For many brands of film this range of linearity is only about two orders of magnitude; one of the primary uses of standards is to verify this range. Temperature and length of exposure can have some effect on the slope of the activity vs. density curve, but the response remains linear. All commercial films that have been tested have been found to be very reproducible from one lot to another.

Direct comparisons between dissection and WBA for quantitation must be interpreted properly. Only tissues with a homogeneous distribution are valid for accuracy. Any degree of inhomogeneity in the tissue destroys the accuracy of the dissection technique although the number obtained by organ dissection may be precise. It is accurate for no single area within that inhomogeneity. On the other hand, the precision with quantitation by WBA can be within $\pm 5 \%$. Considering the advantages of knowing the intraorgan. distribution of this radioactivity, $5 \%$ variation is infinitely better than even a much smaller variability when one does not know the intraorgan distribution.

We see three issues to be resolved before there is widespread recognition of the utilization of WBA. The first of these is the general recognition that there is an adequate degree of quantitation by WBA. The second issue is the chemical identification of the radioactivity. Obviously with resolution of smaller areas of localization, chemical identification of that radioactivity becomes more difficult. Any improvements in techniques for providing this identification in very small areas should greatly facilitate the recognition of WBA. The third issue is that of the acceptance of the technique by official agencies, particularly in the United States. Most of us assume that this lack of acceptance is simply due to conservative attitudes together with a lack of full appreciation of the potential of whole-body autoradiography.

In conclusion, whole-body autoradiography provides as much information as the dissection technique for biological tissues and on balance, considering precision and accuracy, is better for quantitation of concentrations in whole organs. WBA provides quantitation of areas within organs such as cellular layers which are virtually impossible to analyze with dissection. The resolution of quantitation within organs with WBA provides information on potential mechanisms of action that cannot be done with dissection. Those of us involved in WBA should consider the development of a standard protocol, perhaps for Good Laboratory Practice, which could be used to allay some of the reluctance to the technique by regulatory agencies. Finally, efforts should be made, particularly in the United States, to acquaint scientists, as well as regulatory agencies, who are unfamiliar with WBA with the unique advantage of this technique.

\section{References}

1) Ullberg, S. Studies on the distribution and fate of $S^{35}$-labelled benzylpenicillin in the body. Acta Radiol Suppl. 118: 1-110, 1954.

2) Warrander, A. Unpublished results of questionnaire on "Preclinical metabolism and pharmacokinetic prospects for harmonisation," 1992.

3) Franklin, E. R. Factors affecting the sensitivity of X-ray films used for whole-body autoradiography. Xenobiotica 13: 163-169, 1983. 
4) Deak, S. T., Csaky, K. G. and Waddell, W. J. Localization and histochemical correlation of ${ }^{73} \mathrm{As}$ by whole-body autoradiography in mice. J. Toxicol. Environ. Health 1 : 981-984, 1976.

5) Egashira, T. and Waddell, W. J. Histochemical localization of monoamine oxidase in whole-body, freeze-dried sections of mice. Histochem. J. 16: 919-929, 1984.

6) Egashira, T. and Waddell, W. J. Histochemical localization of primary and secondary alcohol dehydrogenases in whole-body, freeze-dried sections of mice. Histochem. J. 16: 931-940, 1984.

7) Waddell, W. J., Ullberg, S. and Marlowe, C. Localization of the bicarbonate and carbonate pools by whole-body autoradiography. Arch. Int. Physiol. Biochim. 77: 1-9, 1969.

8) Waddell, W. J. The distribution of cortisone ${ }^{-14} \mathrm{C}$ in pregnant mice. Teratology 4: 355 $365,1971$.

9) Waddell, W. J. and Mirkin, B. L. Distribution and metabolism of diphenylhydantoin${ }^{14} \mathrm{C}$ in fetal and maternal tissues of the pregnant mouse. Biochem. Pharmacol. 21: 547$552,1972$.

10) Blomquist, L. and Hanngren, $\AA$. Fluorescence techniques applied to whole body sections for distribution studies of tetracyclines. Biochem. Pharmacol. 15: 215-219, 1966.

11) Waddell, W. J. and Marlowe, C. Localization of $\left[{ }^{14} \mathrm{C}\right]$ nitrosonornicotine in tissues of the mouse. Cancer Res. 40: 3518-3523, 1980.

12) Marlowe, C. and Waddell, W. J. Affinity of $\left[{ }^{14} \mathrm{C}\right]$ nitrosopiperidine and metabolites for mouse epithelial tissues. Toxicol. Appl. Pharmacol. 67: 110-116, 1983.

13) Sorokin, S. P. The respiratory system. In: Histology (L. Weiss and R. O. Greep, eds.), 4th edition, pp. 765-830, McGraw-Hill, New York, 1977.

14) Waddell, W. J. and Marlowe, C. Tissue and cellular disposition of paraquat in mice. Toxicol. Appl. Pharmacol. 56: 127-140, 1980.

15) Waddell, W. J. Localization of drugs in tissues with respect to their physiological actions. Annu. Rev. Pharmacol 13: 153-168, 1973.

16) Waddell, W. J. and Marlowe, C. Inhibition by alcohols of the localization of radioactive nitrosonornicotine in sites of tumor formation. Science 221: 51-53, 1983.

17) Irons, R. D. and Gross, E. A. Standardization and calibration of whole-body autoradiography for routine semiquantitative analysis of the distribution of ${ }^{14} \mathrm{C}$-labeled compounds in animal tissues. Toxicol. Appl. Pharmacol. 59: 250-256, 1981.

18) Yonekura, Y, Brill, A. B., Som, P., Bennett, G. W. and Fand, I. Quantitative autoradiography with radiopharmaceuticals, Part 1 . Digital film-analysis system by videodensitometry: concise communication. J. Nucl. Med. 24: 231-237, 1983.

19) Schweitzer, A., Fahr, A. and Niederberger, W. A simple method for the quantitation of ${ }^{14} \mathrm{C}$-whole-body autoradiographs. Appl. Radiat. Isot. 38: 329-333, 1987.

20) McEachron, D. L., Gallistrel, C. R., Eilbert, J. L. and Tretiak, O. J. The analytical and functional accuracy of a video densitometry system. J. Neurosci. Methods 25: 63$74,1988$.

21) Ito, T. and Brill, A. B. Validity of tissue paste standards for quantitative whole-body autoradiography using short-lived radionuclides. Appl. Radiat. Isot. 41: 661-667, 1990.

22) Sainio, E.-L. and Sainio, P. A quantitative method for measuring labeled compounds with whole-body autoradiography in tissue sections. J. Phamacol. Methods 26: 53-59, 1991. 